\title{
FITTINGNESS AND GOOD REASONING
}

\author{
John Brunero
}

$\longrightarrow$

TONOR MCHUGH and Jonathan Way have defended a view of good reasoning according to which good reasoning is explained in terms of the preservation of fittingness. According to the Fittingness View (FV):

It is good reasoning to move from $P_{1} \ldots P_{n}$ to $C$ iff, and because, normally, if $P_{1} \ldots P_{n}$ are fitting, $C$ is fitting too. ${ }^{1}$

The FV does well in accounting for good deductive reasoning. It is often remarked that good deductive reasoning is truth preserving. For instance, when I reason from my belief that $P$ and my belief that $P \rightarrow Q$ to the belief that $Q$, my reasoning is truth preserving in that if $P$ and $P \rightarrow Q$ are both true, then $Q$ is true too. If we now add in the plausible assumption that a belief is fitting if and only if it is true, we can understand my reasoning here as fittingness preserving as well. ${ }^{2}$ And this preservation of fittingness, according to FV, explains why my modus ponens reasoning here is good reasoning.

The FV extends to cover good practical reasoning as well. But, to do so, McHugh and Way must tell us when intentions are fitting. They adopt Nishi Shah's suggestion that the standard of fittingness for intention is permissibility: "it is fitting to intend to $F$ just when it is permissible to F." Consider now a case of practical reasoning from intended ends to necessary means. (I will adopt the familiar convention of listing the relevant attitude in the left-hand column and the contents of the attitude in the right-hand column, drawing a line to separate the "premise-attitudes" from the "conclusion-attitude.")

1 McHugh and Way, "What Is Good Reasoning?" 170. See also their "Broome on Reasoning," sec. 3. The FV quoted here is just a first pass, since they also add, to deal with a certain kind of counterexample involving necessarily fitting (or unfitting) attitudes, the condition that the fittingness must be preserved "because of some relationship between the premise-responses and the conclusion-response" ("What Is Good Reasoning?" 168). But I will set this restriction aside since it will not be relevant to the argument I develop in this discussion note.

2 McHugh and Way, "What Is Good Reasoning?" 165.

3 See McHugh and Way, What Is Good Reasoning?” 165. 


\begin{tabular}{ll}
$\begin{array}{ll}\text { Intention } & \text { I shall } E . \\
\text { Belief } & \text { I shall } E \text { only if I } M .\end{array}$ \\
\hline Intention & I shall $M$.
\end{tabular}

This counts as good reasoning because it is fittingness preserving. In other words, if the premise-attitudes are fitting, so is the conclusion-attitude. To see this, note that if the premise-intention is fitting, then it is permissible to $E$. And, if the premise-belief is fitting (true), then I shall $E$ only if I $M$. But this guarantees that the conclusion-intention is fitting, provided that we adopt the following plausible transmission principle:

If your $E$-ing is permissible, and you will $E$ only if you $M$, then it is permissible to $M^{4}$

Since this reasoning is fittingness preserving, the FV allows us to count it as good reasoning as well.

McHugh and Way have offered us a novel account of good reasoning that covers standard instances of good deductive and instrumental reasoning (as well as many other kinds of reasoning I will not discuss here). But I will argue in this discussion note that the FV is incorrect. Specifically, I will argue (section I) that it is possible for the transition from $P_{1} \ldots P_{n}$ to $C$ to be fittingness preserving without that transition being an instance of good reasoning. In short, not all fittingness-preserving transitions in thought involve good reasoning. I will then consider (section II) possible replies to the objection, and respond to them.

Let us consider an example of what strikes me as very bad reasoning. Suppose I reason as follows:

\begin{tabular}{ll} 
Intention & I shall $E$. \\
Belief & $M$-ing is not permissible. \\
\hline Belief & $M$-ing is not necessary for $E$-ing.
\end{tabular}

Consider a specific instance of this pattern of reasoning. Suppose I intend to get to the airport on time, and believe that speeding is not permissible. Now suppose that, on the basis of these two attitudes, I come to form the belief that speeding

4 McHugh and Way, "What Is Good Reasoning?" 165 . They write: "If it is fitting to intend to $E$, then it is permissible to $E$. And if it is permissible to $E$ and $M$ is a necessary means to $E$, then it is also permissible to $M$. Thus it is fitting to intend to $M$." 
is not necessary for getting to the airport on time. This is bad reasoning. ${ }^{5}$ The conclusion of my reasoning is an ordinary belief about the world, namely, that I can get to the airport on time without speeding. But I do not arrive at this belief by considering evidence for its contents; I do not, for instance, reason from the contents of beliefs about how far I am from the airport, what the speed limit is, and so forth. Indeed, it does not seem as though I have any evidential basis for this belief whatsoever, so far as this line of reasoning goes. The only belief from which I reason is a belief about the impermissibility of speeding. But that is hardly a good basis for drawing a conclusion about the possibility of getting to the airport in time without speeding. This transition in thought is not one that we should declare to be an instance of good reasoning. At best, it seems to be a kind of wishful thinking.

However, this transition in thought is fittingness preserving. In other words, if the premise-attitudes are fitting, then so is the conclusion-attitude. Note that if the premise-intention is fitting, then it is permissible to $E$. And if the premise-belief is fitting (true), then it is not permissible to $M$. And these would guarantee the fittingness of the conclusion-belief provided that we work with the same transmission principle we employed above in explaining why instrumental reasoning to necessary means counts as good reasoning:

If your $E$-ing is permissible, and you will $E$ only if you $M$, then it is permissible to $M^{6}$

From that transmission principle, and the permissibility of $E$-ing and impermissibility of $M$-ing, it follows that it is not the case that you will $E$ only if you $M$. And that guarantees that my conclusion-belief (that $M$-ing is not necessary for $E$-ing) is fitting (true) if my premise-attitudes are fitting.

This example suffices to show that the FV is incorrect: it is possible for a transition from premise-attitudes to a conclusion-attitude to be fittingness preserving (in that if $P_{1} \ldots P_{n}$ are fitting, $C$ is fitting too) without that transition amounting to a case of good reasoning. This is not the place to defend an alternative account of good reasoning. But it is worth noting that other theories of good reasoning are better positioned to explain why my reasoning in the airport example above is not good reasoning. For instance, on the view recently defended by Jonathan Dancy, good reasoning to a belief that $P$ will involve, among other

5 The style of objection here resembles the "asymmetry" objections to wide-scope rational requirements, first put forth by Schroeder, “The Scope of Instrumental Reason”; and Kolodny, "Why Be Rational?"

6 This is logically equivalent to: if your $E$-ing is permissible, and your $M$-ing is not permissible, then it is not the case that you will $E$ only if you $M$. 
things, one's proceeding from the considerations that favor my believing $P$ to my so believing. ${ }^{7}$ And in the airport example, I do not proceed from any such favoring considerations. So, we can explain why this is bad reasoning. More importantly, Dancy's theory, and others in the same ballpark, need not be committed, as McHugh and Way's theory is, to counting the airport example as an instance of good reasoning.

One might wonder about the extent to which my objection to the FV depends upon McHugh and Way's particular suggestion, taken from Shah, that the standard of fittingness for intentions is permissibility. After all, Shah's suggestion does not appear to be an essential feature of their view. They tell us that they are adopting the suggestion "for illustrative purposes." And in another paper published around the same time, they tell us that the fittingness of intentions is a matter of whether they are "choiceworthy," without telling us the difference, if any, between permissibility and choice-worthiness. ${ }^{9}$ Could they avoid my objection, and save the FV, simply by abandoning the suggestion that an intention to $F$ is fitting just when $F$-ing is permissible and replacing this view with another view of fitting intentions?

While it is hard to assess the reply in advance of any particular proposal, I think there are reasons to be skeptical that any such easy fix would be available. For on any view of the fittingness of intentions, the defender of the FV would have to employ some transmission principle to account for good instrumental reasoning, and the worry is that we could then use that same transmission principle to generate counterexamples like the one given in the previous section. For instance, suppose that we took the standard of fittingness of intentions to be choice-worthiness (so that an intention to $F$ is fitting just when $F$-ing is choice-worthy). To explain how good instrumental reasoning is fittingness preserving, we would then need some transmission principle along the following lines:

If your $E$-ing is choice-worthy, and you will $E$ only if you $M$, then your $M$-ing is choice-worthy.

This would ensure that good instrumental reasoning is fittingness preserving (in that if both your intention to $E$ and your belief that you will $E$ only if you $M$ are fitting, then your intention to $M$ is fitting too). But the problem is that, assum-

7 Dancy, Practical Shape, esp. ch. 4.

8 McHugh and Way, "What Is Good Reasoning?” 164.

9 McHugh and Way, "What Is Reasoning?" 178. 
ing choice-worthiness is the standard of fittingness for intentions, this principle would also have it come out that the following pattern of intuitively bad reasoning (a slight variation on the pattern from section $\mathrm{I}$ ) is fittingness preserving:

\begin{tabular}{ll} 
Intention & I shall $E$. \\
Belief & $M$-ing is not choice-worthy. \\
\hline Belief & $M$-ing is not necessary for $E$-ing.
\end{tabular}

And so we would encounter the same kind of problem on this view of what makes intentions fitting.

Perhaps another strategy of reply available to McHugh and Way would be the bullet-biting strategy of maintaining that my purported counterexample in section I is in fact a good pattern of reasoning. They could argue that we are inclined to think it is a bad pattern only because we confuse it with a closely related pattern that is in fact bad:

\begin{tabular}{ll} 
Belief & I will $E$. \\
Belief & $M$-ing is not permissible. \\
\hline Belief & $M$-ing is not necessary for $E$-ing.
\end{tabular}

The confusion is a natural one since English phrases like "I shall E" could be used to express either an intention or a belief. This strategy of reply is inspired by McHugh and Way's treatment of an anticipated objection: that their account would allow for a transition from an intention to $E$ to a belief that $E$-ing is permissible to count as good reasoning. They reply that this transition is in fact good reasoning, and we think it is bad reasoning only because we confuse it with what is in fact bad reasoning: transitioning from a belief that one will $E$ to a belief that $E$-ing is permissible. ${ }^{10}$

I am not convinced by this line of reply, neither as a reply to the current objection, nor as a reply to the objection they anticipate. (I will focus here on the former, but the same points would apply to the latter.) Of course, I agree that the pattern above involving two premise-beliefs and a conclusion-belief is not good reasoning. But note that this does nothing to show that my counterexample, which starts instead from an intention, does involve good reasoning. Why not just say that neither pattern is a pattern of good reasoning? Moreover, the claim that we think such reasoning is bad only because we are confusing it with the above reasoning starting with a belief does not strike me as very plausible. We do not suffer from this confusion in general. For instance, we are perfectly capable of understanding good instrumental reasoning as reasoning that proceeds from an intention, not a belief. So why would we be confused about starting points 10 McHugh and Way, "What Is Good Reasoning?” 171-72. 
in this particular case? Additionally, even if we did suffer from such confusion, it seems easily remedied: we could set up the example to make it clear that the reasoning proceeds from the contents of an intention, not the contents of an associated belief. One way-but not the only way-to do this would be to set up the example so that one intends to $E$ but does not have the associated belief that one will $E$. (Standard examples of this possibility include cases of difficult attempts - for example, intending to make a half-court basketball shot while not believing one will succeed-or anticipated distraction, as in Bratman's famous case of the bicyclist who intends to stop by the bookstore, but, given his tendency to go on autopilot, is agnostic about whether he will. ${ }^{11}$ ) In such cases, it is harder to think that we are confusing an intention to $E$ with a belief that one will $E$, since the agent has only the former.

Another line of reply available to McHugh and Way would draw upon their distinction between good reasoning and competent reasoning. Good reasoning involves conformity with a good pattern. But there is no guarantee that a token piece of reasoning in accordance with a good pattern is done competently. ${ }^{12}$ It could be that people conform to the good pattern accidentally, perhaps because they are not following the good pattern, but instead following some other bad pattern that fortunately leads them to conform to the good pattern. ${ }^{13}$ (They explain the distinction by noting a familiar, analogous one in ethics: doing the right thing does not guarantee that you have acted well, since you may do the right thing for the wrong reasons.) As they note, "At the least, competent reasoning requires that you follow a good pattern." Using this distinction, $\mathrm{McHugh}$

See Bratman, Intentions, Plans, and Practical Reason, 37. Some philosophers hold the view that intentions to $E$ always involve belief that one will $E$, and so they would deny that in these examples, one, strictly speaking, intends to make the shot and intends to stop by the bookstore. However, they would likely concede that the cases involve some related attitude-perhaps we might call it a goal instead of intention - that could be the starting point for good instrumental reasoning. (For instance, see Velleman, Practical Reflection, 112, on the "plan-state" and "goal-state" senses of "intention." For Velleman, intentions to $E$ in the former sense involve believing one will $E$. But intentions in the "goal-state" sense need not involve any such belief. However, intentions in the goal-state sense could be the basis for good instrumental reasoning.) And if the attitude, whatever we call it, could be the basis for good instrumental reasoning, there is no obstacle to it being the basis for bad reasoning as well, as in the pattern of reasoning discussed in section $\mathrm{I}$.

12 As they put it, "to say that it is good reasoning to move from some premise-responses to a conclusion-response is not by itself to say anything about whether any token piece of reasoning was done well, or as we shall say, competently" ("What Is Good Reasoning?" 155).

13 See their example, taken from John Turri ("On the Relationship Between Propositional and Doxastic Justification"), of compliance with modus ponens when following the faulty pattern of modus profusus. McHugh and Way, "What Is Good Reasoning?" 156. 
and Way could argue that my airport example from section I is a case of good reasoning, and hence no threat to the $\mathrm{FV}$, but it is not reasoning that is done competently.

However, although the airport example is a token piece of reasoning, the problem seems to be with the pattern exemplified there, not with the way the particular reasoner in that example complies with the pattern. In other words, the following pattern does not strike us as a good pattern:

\begin{tabular}{ll} 
Intention & I shall $E$. \\
Belief & $M$-ing is not permissible. \\
\hline Belief & $M$-ing is not necessary for $E$-ing.
\end{tabular}

To make it more clear that the problem lies with the pattern itself, rather than with the way in which some particular agent complies with it, we could stipulate that the usual threats to competence in reasoning are not present. For instance, we could stipulate that our agent complies with the pattern non-accidentally, and that he is following this, and not some other, pattern. If we add such features to the airport example, it will still strike us as a case of bad reasoning, and hence be a counterexample to the FV. (Similarly, in ethics, if one tried to deflect some counterexample to a theory of right action by holding that it confuses acting rightly and acting for the right reasons, we could stipulate that the relevant agent acts for right reasons - whatever that amounts to-and then see whether we still find the counterexample to be forceful.) In short, in the example I give in section I, above, the problem seems to be with the pattern exemplified, rather than with the particular way in which an agent conforms to that pattern in a token piece of reasoning.

Yet another line of reply is available to McHugh and Way that, like some of the possible replies considered above, involves them biting the bullet and holding that my example does indeed involve good reasoning, while giving a debunking explanation of why we are inclined to think otherwise: they could hold that we think there is something wrong in my example not because of a defect in the reasoning, but because of a defect in the starting points of the reasoning. It is widely accepted that one can reason well from defective starting points. For instance, one can reason well via modus ponens from a belief that $P$ and a belief that $P \rightarrow Q$ to a belief that $Q$, even if one's premise-beliefs are false and unjustified. ${ }^{14}$ The badness of the starting points need not affect the quality of one's reasoning from them. So, if McHugh and Way can show that we think there is something wrong

14 McHugh and Way themselves make this familiar observation: "To say that some reasoning is good, in our sense, is to say something about the transition between attitudes, rather than something about the attitudes you begin from" ("What Is Good Reasoning?" 155). 
with the airport example only because we think there is a defective starting point, they could save the FV, which is a view only about the goodness of transitions from those starting points.

In support of the idea that that my airport example (and any other example exemplifying the pattern of reasoning outlined in section I) involves a defective starting point, McHugh and Way could argue that there is something inappropriate about intending to $E$ whenever one is wondering about whether $E$ can be accomplished in a permissible way. And they could then maintain that whenever one follows the pattern of reasoning outlined in section I, one must be wondering about whether $E$ can be accomplished in a permissible way.

I have two objections to this proposed reply. First, it is not clear to me that we must consider the example as one in which the reasoner is wondering about whether he can $E$ in a permissible way. It is supposed to be an example of bad (fittingness-preserving) reasoning, and I am free to set up the example so that our bad reasoner is wondering instead about the ordinary empirical question of whether he can get to the airport in time without speeding, and reasoning to a conclusion in a very bad, but fittingness-preserving, way. Second, even if we allow that the example involves him wondering about whether he can $E$ in a permissible way, and we allow that this makes his intention to $E$ a defective starting point, it is not clear to me why we cannot say that both the starting point and the transition from that starting point are bad. After all, we are perfectly capable of identifying good instrumental reasoning from bad starting points-including from intentions that are defective in precisely this proposed way. ${ }^{15}$ So, why would we have trouble seeing the allegedly good reasoning in the airport example?

I will consider one final line of reply available to McHugh and Way, one that again aims to show that the counterexample I presented to the FV in section I does not work because, contrary to appearances, the reasoning there is actually good reasoning. If we start from $\mathrm{McHugh}$ and Way's thought that reasoning to an intention aims at permissibility, we could argue that when one intends to $E$, and this intention is fitting (in that $E$-ing is permissible), the intention to $E$ would be based on those considerations that favor E's permissibility. And if that is so, then one's intention to $E$ will reflect E's permissibility. But then, according to this line of reply, our reasoner will have the evidence that will license him

15 Relatedly, as Jay Wallace observes, there are familiar cases of what Wallace (following Aristotle) calls "cleverness," in which one intends some end one knows to be impermissible, but in which one nonetheless reasons well in pursuit of that end ("Normativity, Commitment, and Instrumental Reason"). It does not seem as though the defective starting points affect our judgment about the goodness of the instrumental reasoning proceeding from them. So why should we think it would do so in the airport example? 
to conclude that $M$-ing is not necessary for $E$-ing, given M's impermissibility. So, it would come out that the reasoning in our example is good reasoning after all. (Note that this line of reply would not commit McHugh and Way to the implausibly strong claim that intending to $E$ involves believing $E$ is permissible. Rather, it would just commit them to the idea that intending to $E$ is based on the considerations favoring E's permissibility, which in turn provides the relevant evidential basis that allows us to count the reasoning as good reasoning.)

In reply, we can note that since we need only one case to provide a counterexample to McHugh and Way's view, we could set up the example so that the intention to get to the airport is not in fact a fitting intention-or, we could even allow that it is fitting, but hold that it is not based on the considerations that point toward its fittingness, but on other considerations. (All of this is compatible with the thought that reasoning to an intention aims at fittingness; sometimes such reasoning simply fails to hit its aim, resulting in intentions that are not based on the considerations pointing to fittingness.) If we stipulate that these are features of the example-and this stipulation does not strike me as incoherent or otherwise implausible - then we will have an example of fittingness-preserving reasoning where the proposed strategy for vindicating it as good reasoning would be unavailable, since we would not be able to claim that the intention is itself based on considerations pointing to fittingness.

However, perhaps the actual fittingness of E-that is, E's actually being permissible-is not needed to get this defense of McHugh and Way off the ground. Perhaps they could argue that an agent's intention to $E$ will be taken by the agent to be based on considerations supporting E's permissibility. (Whether the intention is actually so based, on the current proposal, is neither here nor there.) Again, on this strategy, we are supposing that this state of taking the intention to be based on considerations supporting E's permissibility falls short of believing that $E$ is permissible. Perhaps this will provide a way of vindicating the reasoning in my airport example as good reasoning.

The question at this point would be whether we should accept this view about the nature of intention. In support of this view, one could claim that one cannot just decide to $E$ in the absence of taking there to be considerations that support E's permissibility. But this claim can be read in two ways. On one plausible reading of it-a reading perhaps supported by certain defenses of versions of the Guise of the Good thesis-deciding to $E$ involves taking $E$ to be supported by some reasons - that is, by some considerations that cast $E$-ing in a favorable light in some respect, and to some degree. ${ }^{16} \mathrm{~A}$ second, implausibly strong, reading

16 See, for instance, Raz, "On the Guise of the Good." It would take us too far afield to explore the question of which, if any, version of the Guise of the Good thesis is correct. However, 
would hold that deciding to $E$ involves taking $E$ to be supported by considerations that sufficiently support E-ing. This is implausibly strong-as defenders of the Guise of the Good thesis would likely concede-since standard cases of weakness of will (e.g., deciding to have the chocolate cake I know I should not have) do not involve my taking the reasons (e.g., the tastiness of the cake) on which my decision is based to be sufficient. The problem, however, for this proposed defense of McHugh and Way, is that the implausibly strong reading is what would be needed to vindicate the reasoning in the airport example as good reasoning. Think for a moment about reasoning involving beliefs. While it is good reasoning to transition from a belief that E-ing is permissible and a belief that $M$-ing is not permissible to a belief that $M$-ing is not necessary for $E$-ing, it is not good reasoning to transition from a belief that there is some reason to $E$ and a belief that $M$-ing is not permissible to a belief that $M$-ing is not necessary for $E$-ing. We are of course exploring a strategy that avoids the thesis that intending to $E$ involves beliefs about the reasons for $E$-ing. But an analogous point would hold. The weak, plausible reading, according to which deciding to $E$ involves taking there to be some reason for $E$-ing, would not be strong enough to vindicate the reasoning in the airport example as good reasoning. The second, stronger reading would be strong enough to vindicate the reasoning, but it is an implausibly strong thesis about the nature of intention. Either way, the strategy runs into difficulty.

In conclusion, I hope to have shown in this discussion that fittingness preservation and good reasoning can come apart, since not all fittingness-preserving transitions make for good reasoning. I have presented (in section I) a counterexample to the FV and (in section II) discussed difficulties faced by various possible replies to that counterexample. ${ }^{17}$

\section{University of Nebraska-Lincoln jbrunero2@unl.edu}

for reasons given in the text below, I think my objection to McHugh and Way can stand independently of this question.

I commented on an earlier version of "What Is Good Reasoning?" presented by Jonathan Way at the NYU Abu Dhabi Normativity and Reasoning Workshop. Thanks to Way and the other participants for helpful discussions. More recently, I taught the paper in a seminar on practical reasoning at the University of Nebraska-Lincoln. Thanks to Joe Mendola, Mark van Roojen, and the graduate students in that seminar. (Thanks especially to Mark for telling me to write this point up and send it to JESP.) My greatest debt is to three excellent referees for JESP, whose various helpful objections and comments are considered in section II. 


\section{REFERENCES}

Bratman, Michael. Intentions, Plans, and Practical Reason. Cambridge, MA: Harvard University Press, 1987.

Dancy, Jonathan. Practical Shape: A Theory of Practical Reasoning. Oxford: Oxford University Press, 2018.

Kolodny, Niko. "Why Be Rational?” Mind 114, no. 455 (July 2005): 509-63.

McHugh, Conor, and Jonathan Way. "Broome on Reasoning." Teorema 34, no. 2 (2015): 131-40.

- "What Is Good Reasoning?" Philosophy and Phenomenological Research 96, no. 1 (January 2018): 153-74.

- "What Is Reasoning?” Mind 127, no. 505 (January 2018): 167-96.

Raz, Joseph. "On the Guise of the Good." In Desire, Practical Reason, and the Good, edited by Sergio Tenenbaum, 111-37. Oxford: Oxford University Press, 2010.

Schroeder, Mark. “The Scope of Instrumental Reason." Philosophical Perspectives 18, no. 1 (November 2004): 337-64.

Turri, John. "On the Relationship Between Propositional and Doxastic Justification." Philosophy and Phenomenological Research 80, no. 2 (March 2010): $312-26$.

Velleman, J. David. Practical Reflection. Princeton: Princeton University Press, 1989.

Wallace, R. Jay. "Normativity, Commitment, and Instrumental Reason." Philosophers' Imprint 1, no. 3 (December 2001): 1-26. 